OPEN ACCESS

Edited by:

Oliver T. Wolf,

Ruhr University Bochum, Germany

Reviewed by:

Kevin D. Beck,

Rutgers, New Jersey Medical School,

USA

Kevin S. LaBar,

Duke University, USA

${ }^{*}$ Correspondence:

Tim Klucken,

Department of Psychotherapy and

Systems Neuroscience, Justus Liebig University Giessen,

Otto-Behaghel-Str. 10 F, 35394

Giessen, Germany

tim.klucken@psychol.uni-giessen.de

Received: 26 February 2015 Accepted: 10 May 2015 Published: 02 June 2015

Citation:

Klucken T, Kruse O, Schweckendiek $J$ and Stark R (2015) Increased skin conductance responses and neural activity during fear conditioning are associated with a repressive coping

Front. Behav. Neurosci. 9:132 doi: 10.3389/fnbeh.2015.00132

\section{Increased skin conductance responses and neural activity during fear conditioning are associated with a repressive coping style}

\author{
Tim Klucken ${ }^{1,2 *}$, Onno Kruse ${ }^{1,2}$, Jan Schweckendiek ${ }^{1,2}$ and Rudolf Stark ${ }^{1,2}$ \\ ${ }^{1}$ Department of Psychotherapy and Systems Neuroscience, Justus Liebig University Giessen, Giessen, Germany, ${ }^{2}$ Bender \\ Institute of Neuroimaging, Justus Liebig University Giessen, Giessen, Germany
}

The investigation of individual differences in coping styles in response to fear conditioning is an important issue for a better understanding of the etiology and treatment of psychiatric disorders. It has been assumed that an avoidant (repressive) coping style is characterized by increased emotion regulation efforts in context of fear stimuli as compared to a more vigilant coping style. However, no study so far has investigated the neural correlates of fear conditioning of repressors and sensitizers. In the present fMRI study, 76 participants were classified as repressors or as sensitizers and were exposed to a fear conditioning paradigm, in which the CS+ predicted electrical stimulation, while another neutral stimulus (CS-) did not. In addition, skin conductance responses (SCRs) were measured continuously. As the main findings, we found increased neural activity in repressors as compared to sensitizers in the ventromedial prefrontal cortex and the anterior cingulate cortex (ACC) during fear conditioning. In addition, elevated activity to the CS+ in amygdala, insula, occipital, and orbitofrontal cortex (OFC) as well as elevated conditioned SCRs were found in repressors. The present results demonstrate increased neural activations in structures linked to emotion down-regulation mechanisms like the ventromedial prefrontal cortex, which may reflect the increased coping effort in repressors. At the same time, repressors showed increased activations in arousal and evaluation-associated structures like the amygdala, the occipital cortex (OCC), and the OFC, which was mirrored in increased SCRs. The present results support recent assumptions about a two-process model of repression postulating a fast vigilant response to fear stimuli, and a second process associated with the down-regulation of emotional responses.

Keywords: classical conditioning, fear, vigilance, sensitizer, amygdala, reappraisal

\section{Introduction}

Coping can be defined as the ability to process and deal with emotional stimuli, e.g. emotion regulation (Goldin et al., 2008). Dysfunctional coping processes in context of fear stimuli are associated with the etiology of psychiatric disorders (Goldin et al., 2014; Sheppes et al., 2015). Fear conditioning is an established model for the development, maintenance, and treatment of psychiatric disorders (Delgado et al., 2006; Schweckendiek et al., 2011). Thus, the identification of individual differences in coping styles, which 
impact fear conditioning, may lead to a better understanding of (dys)functional human behavior.

In fear conditioning paradigms, a neutral stimulus (CS+) is associated with an aversive stimulus (UCS) like electrical stimulation, while a second neutral stimulus (CS-) predicts the absence of the UCS. After a few pairings, increased conditioned responses (CRs) to the $\mathrm{CS}+$ as compared to the $\mathrm{CS}-$ can be observed, e.g., elevated skin conductance responses (SCRs), startle response, changes in subjective ratings, and altered neural activity (Hamm and Weike, 2005; Dunsmoor et al., 2007; Klucken et al., 2009a, 2013a; Tabbert et al., 2011). Regarding the neural correlates of fear conditioning, many studies have identified a fear-network including the amygdala, the nucleus accumbens (NAcc), the anterior cingulate cortex (ACC), the insula, the orbitofrontal cortex (OFC), and the occipital cortex (OCC; Sehlmeyer et al., 2009; Klucken et al., 2012). Thereby, the amygdala plays an important role for the processing of CRs (LaBar et al., 1998). Beside the amygdala, recent studies suggest an involvement of the NAcc for the CS/UCS association (Klucken et al., 2009b; Pohlack et al., 2012; Do-Monte et al., 2013; Bulganin et al., 2014). In addition, blood oxygen level dependent (BOLD) signal change -responses in the (lateral) OFC, the ACC, and the insula have been considered as neural correlates of higher cognitive and interoceptive evaluation processes (O'Doherty, 2007; Caria et al., 2010; Lissek et al., 2014), while OCC activations are often associated with increased (motivated) attention (Bradley et al., 2003).

The coping model of Krohne and colleagues (Krohne et al., 2000) focuses on individual differences in coping styles when confronted with aversive stimuli and has been repeatedly associated with altered physiological (Rohrmann et al., 2003; Klucken et al., 2010), cognitive (Peters et al., 2012), and neural (Rauch et al., 2007, 2014; Paul et al., 2012) responses. In detail, two independent coping styles have gained increased attention: Subjects with a repressive coping style ("repressors") are characterized by cognitive avoidance of fear stimuli to prevent the experience of arousal (Krohne et al., 2000). In contrast, "sensitizers" are supposed to exhibit vigilant, approaching behavior towards negative stimuli (Krohne et al., 2000). Notably, previous studies have reported a paradoxical dissociation effect by showing increased peripheral-physiological responses in repressors as compared to sensitizers, while sensitizers often reported increased subjective distress (Kohlmann et al., 1996; Derakshan and Eysenck, 2001; Rohrmann et al., 2002; Derakshan et al., 2007; for review see: Schwerdtfeger and Kohlmann, 2004; Rofé, 2008).

Regarding neural differences between repressors and sensitizers, current fMRI studies have shown increased responses in motivated-attention related areas like the OCC, but concurrently also in structures that are involved in the suppression and down-regulation of emotions, i.e., the (ventromedial) prefrontal cortex (vmPFC) and the ACC (Rauch et al., 2007, 2014; Paul et al., 2012; Raio and Phelps, 2015). Regarding the amygdala, the few existing results are inconsistent. Dysfunctional cognitive reappraisal was linked to increased amygdala volume in humans (Hermann et al., 2014a). Additionally, a trend-wise increased amygdala activation during the presentation of fearful faces in sensitizers (Rauch et al., 2007) or a negative correlation between amygdala activity and cognitive reappraisal (Hermann et al., 2014b) has been reported. However, another human study found no group differences in amygdala activity between repressors and sensitizers (Rauch et al., 2014). Regarding fear conditioning, only two studies have so far investigated group differences between repressors and sensitizers. The first study found increased conditioned SCRs in repressors as compared to sensitizers (Scarpetti, 1973), while the second study did not find group differences (Urban and Kohlmann, 1994). However, since the focus of the second study was extinction learning, only five CS/UCS pairings were used in the fear acquisition process.

The aim of the present study was to investigate group differences between repressors and sensitizers in fear conditioning as well as the underlying neural correlates. In accordance with the dissociation effect, we expected increased SCRs in repressors as compared to sensitizers. Based on the abovementioned findings, it was hypothesized that repressors would show higher vmPFC, ACC, OCC, and striatal activations in the contrast $\mathrm{CS}+>\mathrm{CS}-$ as compared to sensitizers, while amygdala differentiation was investigated exploratively.

\section{Materials and Methods}

\section{Participants}

For the present study, participants were classified as repressors ( $n=37 ; 19$ male; mean age: $24.7 ;$ SD: 4.91$)$ or sensitizers ( $n=42$; 22 male; mean age: 23.1; SD: 2.76) using the Mainz Coping Inventory (MCI; Krohne et al., 2000). The MCI is a selfreport questionnaire assessing different coping styles by asking for avoidance or vigilance strategies in different fear-relevant situations. In order to include only subjects with a clearly defined coping style, repressors were defined by percentile ranks above 50 on the gender-specific "cognitive avoidance" scale and below 50 on the gender-specific "vigilance" scale, while sensitizers were defined by percentile ranks above 50 on the "vigilance" and below 50 on the "cognitive avoidance" scale. Other coping styles were not included in the analysis due to the lack of clear hypotheses (Krohne et al., 2000). Current or past mental, sexual, or chronic health problems as well as consumption of psychotropic drugs were defined as exclusion criteria. All participants were right-handed, had normal or corrected-tonormal vision, and received 40 Euro for their participation. Participants gave an informed consent. The study was conducted in accordance with the Declaration of Helsinki and was approved by the institutional ethics committee. Three participants (two repressors) were excluded due to excessive $(>6 \mathrm{~mm}$ ) head motion during scanning, leaving 76 participants in the final sample.

\section{Conditioning Procedure}

A differential fear conditioning procedure (each CS: 16 trials) was conducted using colored squares as reinforced conditioned (CS+) or as non-reinforced (CS-) stimuli. Electrical stimulation was used as unconditioned stimulus (UCS; 50\% reinforcement). 
Each CS was presented for $8 \mathrm{~s}$. The UCS (duration= $100 \mathrm{~ms}$ ) was delivered $7.9 \mathrm{~s}$ after the CS+ onset and co-terminated with the CS+ offset. The inter-trial-interval (ITI) ranged from 4.5 to 7 s. Electrodes were fixed to the middle of the left shin and stimulus intensity was set individually to an "unpleasant but not painful" sensation. A custom-made impulse-generator $(833 \mathrm{~Hz})$ provided transcutaneous electrical stimulation (UCS) for $100 \mathrm{~ms}$ through two $\mathrm{Ag} / \mathrm{AgCl}$ electrodes (1 $\mathrm{mm}^{2}$ surface). Because the experiment is part of a larger project investigating fear conditioning, genetics, and different extinction procedures, two different colored CS+ were used. The two CS+ did neither differ significantly in valence, arousal, or UCS-expectancy ratings nor in SCRs (all $p>0.700$ ) or hemodynamic responses, and are therefore analyzed together. Different extinction techniques were also assessed but will be reported elsewhere. The stimuli were projected onto a screen at the back of the scanner (visual field $=18^{\circ}$ ) using an LCD projector and were viewed through a mirror mounted to the head coil. An MRI-compatible video camera was used to check whether participants watched the stimuli.

\section{Skin Conductance Measures}

SCRs were recorded during the complete MR scan using $\mathrm{Ag} / \mathrm{AgCl}$ electrodes [filled with isotonic $(0.05 \mathrm{M} \mathrm{NaCl})$ electrolyte medium] placed hypothenar at the non-dominant (left) hand. The largest difference between a minimum value, which had to occur within a 1-8 s time window after the CS (CS+ or CS-) onset, and the following maximum was counted as the entire interval response (EIR; Pineles et al., 2009). Statistical analyses were performed via Analysis of variance (ANOVA) in a 2 (stimulus: $\mathrm{CS}+$ vs. $\mathrm{CS}-$ ) $\times 2$ (group: repressors vs. sensitizers) $\times 2$ (time: early phase vs. late phase) design followed by Bonferroni-corrected post hoc tests using SPSS 22 (IBM Corporation, Armonk, USA).

\section{Magnetic Resonance Imaging Hemodynamic Activity}

All images were acquired with a 1.5 Tesla whole-body tomograph (Siemens Symphony with a quantum gradient system) with a CP head coil. Structural image acquisition consisted of 160 T1-weighted sagittal images (MPRage, $1 \mathrm{~mm}$ slice thickness; $\mathrm{TR}=1.9 \mathrm{~s} ; \mathrm{TE}=4.16 \mathrm{~ms} ;$ field of view $250 \times 250$ $\mathrm{mm})$. For functional images, a total of 292 images were registered using a $\mathrm{T} 2 *$-weighted gradient echo-planar imaging (EPI) sequence with 25 slices covering the whole brain (5 $\mathrm{mm}$ slice thickness $1 \mathrm{~mm}$ gap; descending slice procedure; $\mathrm{TR}=2.5 \mathrm{~s} ; \mathrm{TE}=55 \mathrm{~ms}$; flip angle $=90$; field of view 192 $\times 192 \mathrm{~mm}$; matrix size $=64 \times 64$; voxel size $=3 \times 3$ $\times 5 \mathrm{~mm}$ ). The orientation of the axial slices was paralleled to the OFC tissue-bone transition. Data were analyzed using Statistical Parametric Mapping (SPM8, Wellcome Department of Cognitive Neurology, London UK; 2008) implemented in MATLAB 7.5 (Mathworks Inc., Sherbourn, MA). Prior to all statistical analyses, data were preprocessed as described before. The experimental conditions were CS+, CS-, UCS+, and UCS- (time corresponding to the UCS after the CS-). In line with the analyses of SCRs, regressors were also split into a first half $\left(\mathrm{CS}_{+_{1}} / \mathrm{CS}-_{1} ; \mathrm{UCS}_{+_{1}} / \mathrm{UCS}_{-}{ }_{1}\right)$ and a second half $\left(\mathrm{CS}+{ }_{2} / \mathrm{CS}-{ }_{2} ; \mathrm{UCS}+_{2} / \mathrm{UCS}-{ }_{2}\right)$ to investigate potential group differences between the early and the late phase of fear conditioning (Straube et al., 2007; Klucken et al., 2015). All regressors were convolved with the hemodynamic response function. The six movement parameters of the rigid body transformation obtained by the realignment procedure were entered as covariates in the model. The voxel-based time series was filtered with a high pass filter (time constant $=128 \mathrm{~s}$ ).

On the group level, two sample $t$-tests were conducted to examine differences between repressors and sensitizers for the contrast $\mathrm{CS}+>\mathrm{CS}-$. Following a worthwhile reviewer's comment, we also correlated fMRI data (CS+- CS-) with SCRs responses for repressors and sensitizers. Whole brain analyses were conducted with $p<0.05$ (family-wise-error corrected (FWE)) and $k>10$ voxels. Region of interest (ROI) analyses were performed using the small volume correction in SPM8 $p<0.05$ (FWE-corrected; $k>5$ voxels).

ACC, amygdala, insula, NACC, OCC masks were taken from the "Harvard-Oxford cortical and subcortical structural atlases" provided by the Harvard Center for Morphometric Analysis. The lateral OFC mask was created with MARINA (Walter et al., 2003). Hermann and colleagues kindly provided the vmPFC mask (Hermann et al., 2012).

\section{Results}

\section{Skin Conductance Responses}

ANOVA showed a significant main effect of stimulus regarding the $\operatorname{EIR}\left(F_{(1,74)}=75.84, p<0.001\right)$ revealing increased SCRs to the CS+ as compared to the CS-. In addition, main effects of time $\left(F_{(1,74)}=86.23, p<0.001\right)$ and group $\left(F_{(1,74)}=4.72, p<0.05\right)$ were observed. More important, a significant stimulus $\times$ group interaction $\left(F_{(1,74)}=18.67\right.$, $p<0.001)$ was observed. Post hoc tests showed that conditioning was successful in both groups (Figure 1), which is reflected in increased SCRs to the CS+ as compared to the CS- (all $p<0.05$ ). Repressors demonstrated stronger CRs than sensitizers in the early as well as in the late phase.

\section{fMRI-Results}

\section{Main Effect of Stimulus (CS+ > CS-)}

Since the main aim of the study was to investigate differences between repressors and sensitizers, we will only briefly report the main effects of conditioning, which have been reported before Sehlmeyer et al. (2009). ROI-analyses revealed significant results in the contrast $\mathrm{CS}+>\mathrm{CS}-$ in all ROIs, further supporting successful CS+/CS- differentiation.

\section{Group Differences in the Contrast CS+ > CS-}

In accordance with the SCRs, a significant association of neural activations with coping style was observed. Whole brain results showed increased activations in the prefrontal cortex $\left(x / y / z=16 / 62 / 19, z_{\max }=5.05, p<0.01\right)$ in repressors as compared to sensitizers for the complete conditioning phase. Regarding the early phase of fear conditioning (CS+1 - CS -1 ), 


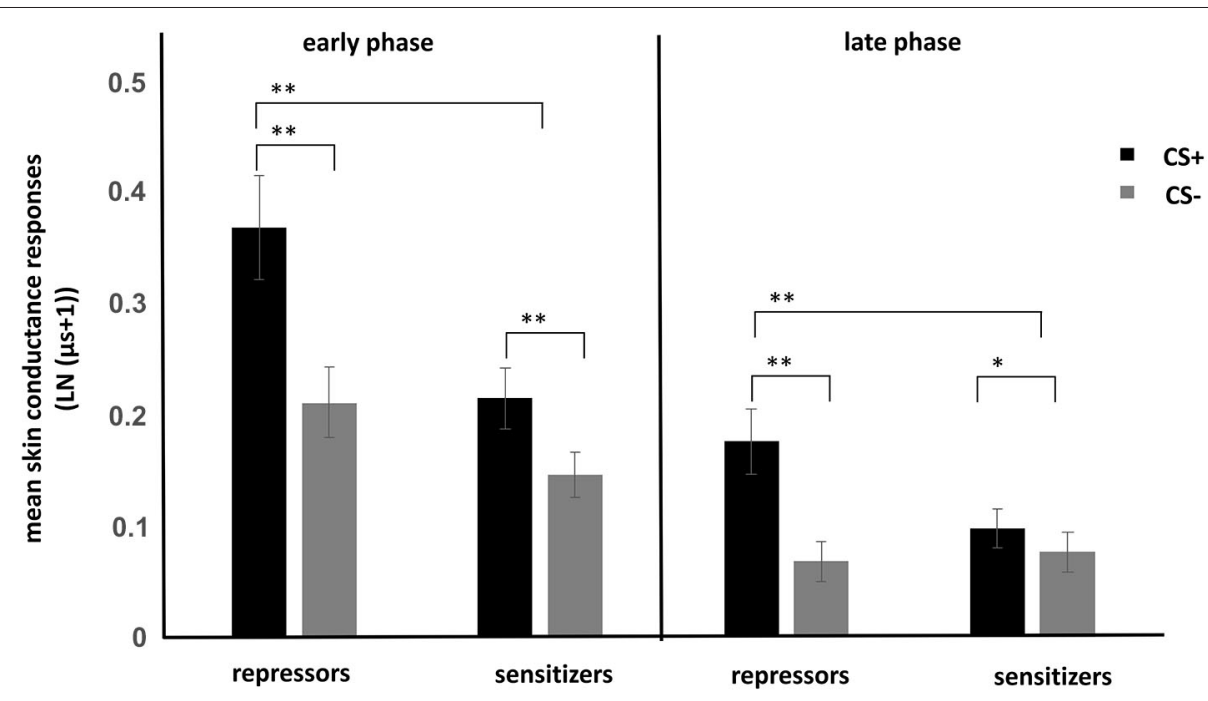

FIGURE 1 | Mean skin conductance responses to CS+ and CS- for repressors and sensitizers for the early (first half of conditioning) and late phase (second half of conditioning).
Enhanced conditioned responses (CRs) were found in the repressor group as compared to the sensitizer group. ${ }^{\star} p<0.05$. ${ }^{\star *} p<0.01$. increased activation was found in repressors as compared to sensitizers in the limbic lobe (middle temporal gyrus) $\left(x / y / z=36 / 11 /-32, z_{\max }=4.86, p<0.05\right)$. In addition, a trend was found in the later phase showing increased activations in repressors in the PFC $\left(x / y / z=18 / 62 / 19, z_{\max }=4.44, p<0.1\right)$.

ROI-analyses further revealed stronger neural activations in the ACC, the insula, the lateral OFC, the OCC, and the vmPFC in repressors compared to sensitizers over the complete conditioning phase as well as increased amygdala activity in the early phase (see Table 1; Figure 2). In addition, no increased activations could be found in sensitizers as compared to repressors. Finally, we correlated SCR data with BOLDresponses for each group separately and found a (trendwise) link between amygdala and SCR activations $(x / y / z=-18 /-13 /-14$, $\left.k=18 z_{\max }=2.74, p=0.058\right)$.

\section{Discussion}

The present study demonstrated that repressors and sensitizers differ in CRs. In detail, repressors displayed higher conditioned SCRs during fear conditioning as compared to sensitizers. In addition, we also found increased neural activations in repressors as compared to sensitizers in the contrast $\mathrm{CS}+-\mathrm{CS}-$ in copingrelevant structures like the vmPFC and the ACC as well as in arousal- and emotion-relevant structures like the amygdala, the OCC, the insula, the NAcc, and the OFC. The data support the view that repressors are characterized by vigilance and downregulation processes in response to fear stimuli.

Regarding vigilance processes, increased amygdala activity is often assumed as neural correlate for an increased sensitivity to the CS+, because amygdala activation constitutes an important process for the stabilization of the learning signal and initiating psychophysiological CRs (Delgado et al., 2006). In addition, insula and OFC activations have been linked to detailed stimulus processes during fear conditioning (Sehlmeyer et al., 2009). Altered occipital activation is often interpreted as a neural correlate of increased attention (Bradley et al., 2003). For instance, enhanced occipital activation has been found during acute presentation of visually aversive stimuli, but also occurs during their anticipation. This has often been referred to as increased motivated attention (Bradley et al., 2003; Ueda et al., 2003; Tabbert et al., 2010; Merz et al., 2012a; Klucken et al., 2013b). This supports the assumption that activation within the OCC is not only stimulus driven, but can also result from top-down processes modulating attention to a stimulus. The increased SCRs together with the neural findings in repressors further underline vigilance processes to the CS+. SCRs are often interpreted as automatic responses to salient cues reflecting increased attention processes to these stimuli. Further, the present data is in line with previous results showing increased SCRs in repressors during fear acquisition (Scarpetti, 1973).

Regarding cognitive avoidance strategies in repressors, we found increased activations in the vmPFC and the ACC. While ACC activation is a common finding in fear conditioning, increased vmPFC activation during fear conditioning is surprising because most studies show an involvement during fear extinction but not during fear conditioning. Many studies linked vmPFC responses to fear inhibition (e.g., during fear extinction) and/or to emotion regulation (Milad et al., 2007; Goldin et al., 2008; Hermann et al., 2009; Merz et al., 2012b; Klucken et al., 2013b; Lissek et al., 2014). In detail, enhanced vmPFC BOLD-responses have been previously reported in other studies using different stimuli and designs (Eippert et al., 2007; Rauch et al., 2007, 2014; Paul et al., 2012), showing an involvement in emotion down-regulation (Goldin et al., 2008; Hermann et al., 2009; Paul et al., 2012), through inhibiting amygdala activity. For instance, one study demonstrated a relation between increased PFC activity during fear conditioning 
TABLE 1 | ROI-activations (CS+ > CS-) for fear conditioning (whole phase).

\begin{tabular}{|c|c|c|c|c|c|c|c|c|c|}
\hline Group analysis & Contrast & Structure & Side & $k$ & $x$ & $y$ & $z$ & $z_{\max }$ & $p$ corr \\
\hline Repressors & $\mathrm{CS}_{+}>$ & $\mathrm{ACC}$ & $\mathrm{L}$ & 650 & -9 & 41 & 7 & 4.00 & 0.008 \\
\hline \multirow[t]{6}{*}{ Sensitizers } & CS- & Amygdala* & $\mathrm{R}$ & 14 & 30 & 2 & -14 & 2.63 & 0.072 \\
\hline & & Insula & L & 253 & -33 & 2 & 7 & 3.86 & 0.006 \\
\hline & & Insula & $\mathrm{R}$ & 138 & 36 & 8 & -14 & 3.67 & 0.012 \\
\hline & & Lateral OFC & $\mathrm{L}$ & 436 & -27 & 23 & -14 & 4.47 & 0.001 \\
\hline & & OCC & $\mathrm{R}$ & 275 & 39 & -91 & 7 & 3.70 & 0.040 \\
\hline & & vmPFC & $\mathrm{L}$ & 111 & -12 & 53 & -2 & 3.30 & 0.044 \\
\hline
\end{tabular}

Region of Interest Analyses, threshold $=p<0.05$ (FWE-corrected; small volume correction according to SPM8). Results are displayed until $p<0.08$. All coordinates refer to MNI space. L, left hemisphere; $R$, right hemisphere. *significant in the early phase of fear conditioning.

and down-regulation strategies (e.g., the imagination of a safe situation) that are similar to the preferred coping-mechanisms of repressors (Delgado et al., 2008). The altered vmPFC activation might thus reflect an increased effort to cope and regulate emotions in repressors as compared to sensitizers. With respect to clinical findings, the present findings (increased SCRs, and BOLD-responses in the fear circuit and vmPFC activations) may mirror the increased negative health outcome in repressors as compared to non-repressors (see Derakshan et al., 2007, for overview). In the review, Derakshan et al. (2007) speculated that the increased reactivity to fear stimuli with the (potential) coping attempt may lead to the increased negative health status in repressors. For instance, longitudinal studies showed a negative correlation between a repressive coping style and treatment success in somatic diseases (Frasure-Smith et al., 2002).

In addition, we found a trendwise significant correlation between amygdala and SCRs in repressors. Previous studies showed that the amygdala is involved in the production of CRs (Petrovic et al., 2008). It is therefore assumable, that amygdala activation may reflect the outcome of fear conditioning and/or the strength of fear memory. However, the result was only a trend and not significant. Therefore, this argumentation should be treated with caution until an independent replication is available.

\section{Future Directions}

In the present study, participants were not explicitly instructed to use emotion-regulation strategies. This is in line with previous

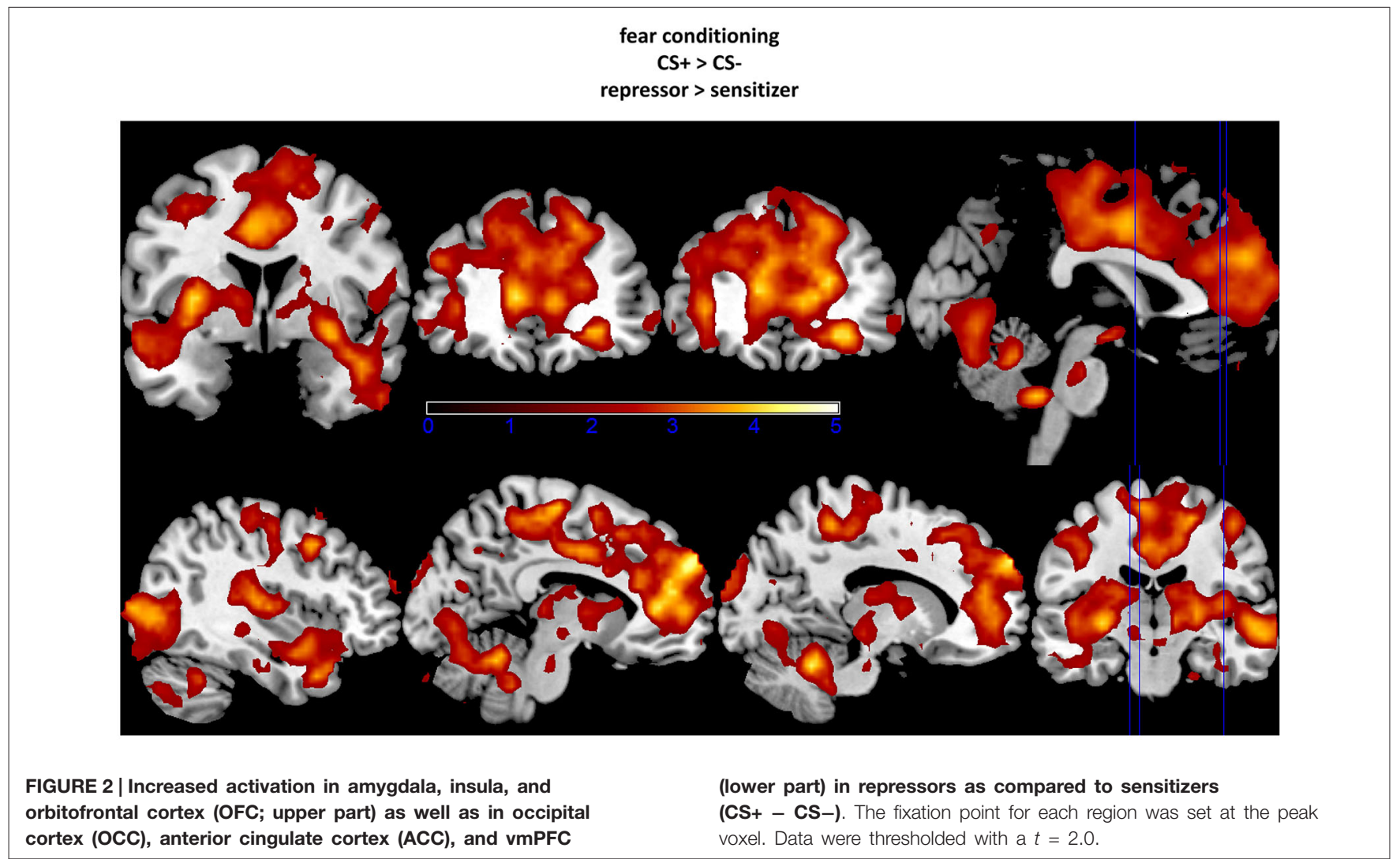


studies with repressors and sensitizers (Rauch et al., 2007, 2014) investigating trait differences in coping styles, rather than state-induced emotion regulation techniques. It therefore has to be kept in mind that the described role of the vmPFC is a post hoc explanation of the observed results. Future studies could investigate if repressors cope more extensively during fear conditioning. In addition, it would be interesting to investigate whether the opposite pattern of results would emerge if sensitizers were instructed to use avoidance strategies, while repressors were instructed to use vigilance coping mechanisms. Finally, some studies showed that vigilance-avoidance responses in repressors are especially visible during very fast responses (e.g., the first $500 \mathrm{~ms}$ after stimulus onset) for every trial, and not over the whole experiment like we found (Derakshan et al., 2007). Using fMRI and BOLD-responses, we were not able to draw such conclusions. Finally, it should be noted that the present study used a fear conditioning design with two CS+. This procedure may lead to increased uncertainty, fear, and stress responses, which could lead to increased group differences and more effort for coping processing as

\section{References}

Bradley, M. M., Sabatinelli, D., Lang, P. J., Fitzsimmons, J. R., King, W., and Desai, P. (2003). Activation of the visual cortex in motivated attention. Behav. Neurosci. 117, 369-380. doi: 10.1037/0735-7044.117.2.369

Bulganin, L., Bach, D. R., and Wittmann, B. C. (2014). Prior fear conditioning and reward learning interact in fear and reward networks. Front. Behav. Neurosci. 8:67. doi: $10.3389 /$ fnbeh.2014.00067

Caria, A., Sitaram, R., Veit, R., Begliomini, C., and Birbaumer, N. (2010). Volitional control of anterior insula activity modulates the response to aversive stimuli. A real-time functional magnetic resonance imaging study. Biol. Psychiat 68, 425-432. doi: 10.1016/j.biopsych.2010.04.020

Delgado, M. R., Nearing, K. I., LeDoux, J. E., and Phelps, E. A. (2008). Neural circuitry underlying the regulation of conditioned fear and its relation to extinction. Neuron 59, 829-838. doi: 10.1016/j.neuron.2008. 06.029

Delgado, M. R., Olsson, A., and Phelps, E. A. (2006). Extending animal models of fear conditioning to humans. Biol. Psychol. 73, 39-48. doi: 10.1016/j.biopsycho. 2006.01.006

Derakshan, N., and Eysenck, M. W. (2001). Effects of focus of attention on physiological, behavioural and reported state anxiety in repressors, lowanxious, high-anxious and defensive high-anxious individuals. Anxiety Stress Coping 14, 285-299. doi: 10.1080/10615800108248358

Derakshan, N., Eysenck, M. W., and Myers, L. B. (2007). Emotional information processing in repressors: the vigilance-avoidance theory. Cogn. Emot. 21, 1585-1614. doi: 10.1080/02699930701499857

Do-Monte, F. H., Rodriguez-Romaguera, J., Rosas-Vidal, L. E., and Quirk, G. J. (2013). Deep brain stimulation of the ventral striatum increases BDNF in the fear extinction circuit. Front. Behav. Neurosci. 7:102. doi: 10.3389/fnbeh.2013. 00102

Dunsmoor, J. E., Bandettini, P. A., and Knight, D. C. (2007). Impact of continuous versus intermittent CS-UCS pairing on human brain activation during pavlovian fear conditioning. Behav. Neurosci. 121, 635-642. doi: 10. 1037/0735-7044.121.4.635

Eippert, F., Veit, R., Weiskopf, N., Erb, M., Birbaumer, N., and Anders, S. (2007). Regulation of emotional responses elicited by threat-related stimuli. Hum. Brain Mapp. 28, 409-423. doi: 10.1002/hbm.20291

Frasure-Smith, N., Lespérance, F., Gravel, G., Masson, A., Juneau, M., and Bourassa, M. G. (2002). Long-term survival differences among low-anxious, high-anxious and repressive copers enrolled in the montreal heart attack readjustment trial. Psychosom. Med. 64, 571-579. doi: 10.1097/01.psy. 0000021950.04969.f8 compared to a differential fear conditioning design with one $\mathrm{CS}+$ only. It is therefore interesting to investigate group differences using paradigms with different complexity and uncertainty to gain a better understanding of repression and sensitization.

In sum, the results clearly support the assumption that a person's coping mode is associated with fear conditioning. We observed increased SCRs and BOLD-responses in subcortical and cortical structures in repressors as compared to sensitizers. These findings contribute to the current debate of the vigilance-avoidance model and provide potential neural mechanisms linked to vigilance and down-regulation processes in repressors.

\section{Funding}

This work was supported by a research grant from the DFG German Research Foundation (KL 2500-1) and by an excellent stipend ("Just'Us") to the first author from the Justus Liebig University Giessen.

Goldin, P. R., Lee, I., Ziv, M., Jazaieri, H., Heimberg, R. G., and Gross, J. J. (2014). Trajectories of change in emotion regulation and social anxiety during cognitive-behavioral therapy for social anxiety disorder. Behav. Res. Ther. 56, 7-15. doi: 10.1016/j.brat.2014.02.005

Goldin, P. R., McRae, K., Ramel, W., and Gross, J. J. (2008). The neural bases of emotion regulation: reappraisal and suppression of negative emotion. Biol. Psychiatry 63, 577-586. doi: 10.1016/j.biopsych.2007.05.031

Hamm, A. O., and Weike, A. I. (2005). The neuropsychology of fear learning and fear regulation. Int. J. Psychophysiol. 57, 5-14. doi: 10.1016/j.ijpsycho.2005.01. 006

Hermann, A., Bieber, A., Keck, T., Vaitl, D., and Stark, R. (2014a). Brain structural basis of cognitive reappraisal and expressive suppression. Soc. Cogn. Affect. Neurosci. 9, 1435-1442. doi: 10.1093/scan/nst130

Hermann, A., Keck, T., and Stark, R. (2014b). Dispositional cognitive reappraisal modulates the neural correlates of fear acquisition and extinction. Neurobiol. Learn. Mem. 113, 115-124. doi: 10.1016/j.nlm.2014. 03.008

Hermann, A., Küpper, Y., Schmitz, A., Walter, B., Vaitl, D., Hennig, J., et al. (2012) Functional gene polymorphisms in the serotonin system and traumatic life events modulate the neural basis of fear acquisition and extinction. PLoS One 7:e44352. doi: 10.1371/journal.pone.0044352

Hermann, A., Schäfer, A., Walter, B., Stark, R., Vaitl, D., and Schienle, A. (2009). Emotion regulation in spider phobia: role of the medial prefrontal cortex. Soc. Cogn. Affect. Neurosci. 4, 257-267. doi: 10.1093/scan/nsp013

Klucken, T., Alexander, N., Schweckendiek, J., Merz, C. J., Kagerer, S., Osinsky, R., et al. (2013a). Individual differences in neural correlates of fear conditioning as a function of 5-HTTLPR and stressful life events. Soc. Cogn. Affect. Neurosci. 8, 318-325. doi: 10.1093/scan/nss005

Klucken, T., Brouwer, A.-M., Chatziastros, A., Kagerer, S., Netter, P., and Hennig, J. (2010). The impact of coping style on gaze duration. PLoS One 5:e15395. doi: 10.1371/journal.pone.0015395

Klucken, T., Kagerer, S., Schweckendiek, J., Tabbert, K., Vaitl, D., and Stark, R. (2009a). Neural, electrodermal and behavioral response patterns in contingency aware and unaware subjects during a picture-picture conditioning paradigm. Neuroscience 158, 721-731. doi: 10.1016/j.neuroscience.2008.09.049

Klucken, T., Kruse, O., Wehrum-Osinsky, S., Hennig, J., Schweckendiek, J., and Stark, R. (2015). Impact of COMT Val158Met-polymorphism on appetitive conditioning and amygdala/prefrontal effective connectivity. Hum. Brain Mapp. 36, 1093-1101. doi: 10.1002/hbm.22688

Klucken, T., Schweckendiek, J., Koppe, G., Merz, C. J., Kagerer, S., Walter, B., et al. (2012). Neural correlates of disgust- and fear-conditioned responses. Neuroscience 201, 209-218. doi: 10.1016/j.neuroscience.2011.11.007 
Klucken, T., Schweckendiek, J., Merz, C. J., Vaitl, D., and Stark, R. (2013b). Dissociation of neuronal, electrodermal and evaluative responses in disgust extinction. Behav. Neurosci. 127, 380-386. doi: 10.1037/a0032331

Klucken, T., Tabbert, K., Schweckendiek, J., Merz, C. J., Kagerer, S., Vaitl, D., et al. (2009b). Contingency learning in human fear conditioning involves the ventral striatum. Hum. Brain Mapp. 30, 3636-3644. doi: 10.1002/hbm.20791

Kohlmann, C.-W., Weidner, G., and Messina, C. R. (1996). Avoidant coping style and verbal-cardiovascular response dissociation. Psychol. Health 11, 371-384. doi: 10.1080/08870449608400265

Krohne, H. W., Egloff, B., Varner, L. J., Burns, L. R., Weidner, G., and Ellis, H. C. (2000). The assessment of dispositional vigilance and cognitive avoidance: factorial structure, psychometric properties and validity of the Mainz coping inventory. Cogn. Ther. Res. 24, 297-311. doi: 10.1023/A:1005511320194

LaBar, K. S., Gatenby, C. J., Gore, J. C., LeDoux, J. E., and Phelps, E. A. (1998). Human amygdala activation during conditioned fear acquisition and extinction: a mixed-trial fMRI study. Neuron 20, 937-945. doi: 10.1016/s08966273(00)80475-4

Lissek, S., Bradford, D. E., Alvarez, R. P., Burton, P., Espensen-Sturges, T., Reynolds, R. C., et al. (2014). Neural substrates of classically conditioned feargeneralization in humans: a parametric fMRI study. Soc. Cogn. Affect. Neurosci. 9, 1134-1142. doi: 10.1093/scan/nst096

Merz, C. J., Tabbert, K., Schweckendiek, J., Klucken, T., Vaitl, D., Stark, R., et al. (2012a). Oral contraceptive usage alters the effects of cortisol on implicit fear learning. Horm. Behav. 62, 531-538. doi: 10.1016/j.yhbeh.2012.09.001

Merz, C. J., Tabbert, K., Schweckendiek, J., Klucken, T., Vaitl, D., Stark, R., et al. (2012b). Neuronal correlates of extinction learning are modulated by sex hormones. Soc. Cogn. Affect. Neurosci. 7, 819-830. doi: 10.1093/scan/nsr063

Milad, M. R., Wright, C. I., Orr, S. P., Pitman, R. K., Quirk, G. J., and Rauch, S. L. (2007). Recall of fear extinction in humans activates the ventromedial prefrontal cortex and hippocampus in concert. Biol. Psychiatry 62, 446-454. doi: 10.1016/j.biopsych.2006.10.011

O'Doherty, J. P. (2007). Lights, camembert, action! The role of human orbitofrontal cortex in encoding stimuli, rewards and choices. Ann. N Y Acad. Sci. 1121, 254-272. doi: 10.1196/annals.1401.036

Paul, V. G., Rauch, A. V., Kugel, H., Ter Horst, L., Bauer, J., Dannlowski, U., et al. (2012). High responsivity to threat during the initial stage of perception in repression: a 3 T fMRI study. Soc. Cogn. Affect. Neurosci. 7, 980-990. doi: 10. 1093/scan/nsr080

Peters, J. H., Hock, M., and Krohne, H. W. (2012). Sensitive maintenance: a cognitive process underlying individual differences in memory for threatening information. J. Pers. Soc. Psychol. 102, 200-213. doi: 10.1037/a0026080

Petrovic, P., Kalisch, R., Pessiglione, M., Singer, T., and Dolan, R. J. (2008). Learning affective values for faces is expressed in amygdala and fusiform gyrus. Soc. Cogn. Affect. Neurosci. 3, 109-118. doi: 10.1093/scan/nsn002

Pineles, S. L., Orr, M. R., and Orr, S. P. (2009). An alternative scoring method for skin conductance responding in a differential fear conditioning paradigm with a long-duration conditioned stimulus. Psychophysiology 46, 984-995. doi: 10. 1111/j.1469-8986.2009.00852.x

Pohlack, S. T., Nees, F., Ruttorf, M., Schad, L. R., and Flor, H. (2012). Activation of the ventral striatum during aversive contextual conditioning in humans. Biol. Psychol. 91, 74-80. doi: 10.1016/j.biopsycho.2012.04.004

Raio, C. M., and Phelps, E. A. (2015). The influence of acute stress on the regulation of conditioned fear. Neurobiol. Stress 1, 134-146. doi: 10.1016/j.ynstr.2014. 11.004

Rauch, A. V., Ohrmann, P., Bauer, J., Kugel, H., Engelien, A., Arolt, V., et al. (2007). Cognitive coping style modulates neural responses to emotional faces in healthy humans: a 3-t fMRI study. Cereb. Cortex 17, 2526-2535. doi: 10. 1093/cercor/bhl158

Rauch, A. V., Ter Horst, L., Paul, V. G., Bauer, J., Dannlowski, U., Konrad, C., et al. (2014). Influence of repressive coping style on cortical activation during encoding of angry faces. PLoS One 9:e112398. doi: 10.1371/journal. pone.0112398

Rofé, Y. (2008). Does repression exist? Memory, pathogenic, unconscious and clinical evidence. Rev. Gen. Psychol. 12, 63-85. doi: 10.1037/1089-2680. 12.1.63

Rohrmann, S., Hennig, J., and Netter, P. (2002). Manipulation of physiological and emotional responses to stress in repressors and sensitizers. Psychol. Health 17, 583-596. doi: 10.1080/08870440290025795

Rohrmann, S., Netter, P., Hennig, J., and Hodapp, V. (2003). Repressionsensitization, gender and discrepancies in psychobiological reactions to examination stress. Anxiety Stress Coping 16, 321-329. doi: 10 . 1080/1061580031000095461

Scarpetti, W. L. (1973). The repression-sensitization dimension in relation to impending painful stimulation. J. Consult. Clin. Psychol. 40, 377-382. doi: 10. 1037/h0034494

Schweckendiek, J., Klucken, T., Merz, C. J., Tabbert, K., Walter, B., Ambach, W., et al. (2011). Weaving the (neuronal) web: fear learning in spider phobia. Neuroimage 54, 681-688. doi: 10.1016/j.neuroimage.2010.07.049

Schwerdtfeger, A., and Kohlmann, C.-W. (2004). Repressive coping style and the significance of verbal-autonomic response dissociations. Adv. Psychol. 136, 239-278. doi: 10.1016/s0166-4115(04)80036-0

Sehlmeyer, C., Schöning, S., Zwitserlood, P., Pfleiderer, B., Kircher, T., Arolt, V., et al. (2009). Human fear conditioning and extinction in neuroimaging: a systematic review. PLoS One 4:e5865. doi: 10.1371/journal.pone.0005865

Sheppes, G., Suri, G., and Gross, J. J. (2015). Emotion regulation and psychopathology. Annu. Rev. Clin. Psychol. 11,379-405. doi: 10.1146/annurevclinpsy-032814-112739.

Straube, T., Weiss, T., Mentzel, H.-J., and Miltner, W. H. R. (2007). Time course of amygdala activation during aversive conditioning depends on attention. Neuroimage 34, 462-469. doi: 10.1016/j.neuroimage.2006. 08.021

Tabbert, K., Merz, C. J., Klucken, T., Schweckendiek, J., Vaitl, D., Wolf, O. T., et al. (2010). Cortisol enhances neural differentiation during fear acquisition and extinction in contingency aware young women. Neurobiol. Learn. Mem. 94, 392-401. doi: 10.1016/j.nlm.2010.08.006

Tabbert, K., Merz, C. J., Klucken, T., Schweckendiek, J., Vaitl, D., Wolf, O. T., et al. (2011). Influence of contingency awareness on neural, electrodermal and evaluative responses during fear conditioning. Soc. Cogn. Affect. Neurosci. 6, 495-506. doi: 10.1093/scan/nsq070

Ueda, K., Okamoto, Y., Okada, G., Yamashita, H., Hori, T., and Yamawaki, S. (2003). Brain activity during expectancy of emotional stimuli: an fMRI study. Neuroreport 14, 51-55. doi: 10.1097/00001756-200301200-00010

Urban, T., and Kohlmann, C.-W. (1994). Vigilance and coping with uncertainty. Z. Differentielle Diagnostische Psychol. 15, 49-62.

Walter, B., Blecker, C., Kirsch, P., Sammer, G., Schienle, A., Stark, R., et al. (2003). "MARINA: an easy to use tool for the creation of masks for region of interest analyses," in 9th International Conference on Functional Mapping of the Human Brain. Available on CD-Rom in NeuroImage 19 (New York, NY, USA).

Conflict of Interest Statement: The authors declare that the research was conducted in the absence of any commercial or financial relationships that could be construed as a potential conflict of interest.

Copyright (C) 2015 Klucken, Kruse, Schweckendiek and Stark. This is an open-access article distributed under the terms of the Creative Commons Attribution License (CC $B Y)$. The use, distribution and reproduction in other forums is permitted, provided the original author(s) or licensor are credited and that the original publication in this journal is cited, in accordance with accepted academic practice. No use, distribution or reproduction is permitted which does not comply with these terms. 